\title{
Endoscopic resection of a giant pedunculated polyp using scissor-type forceps
}
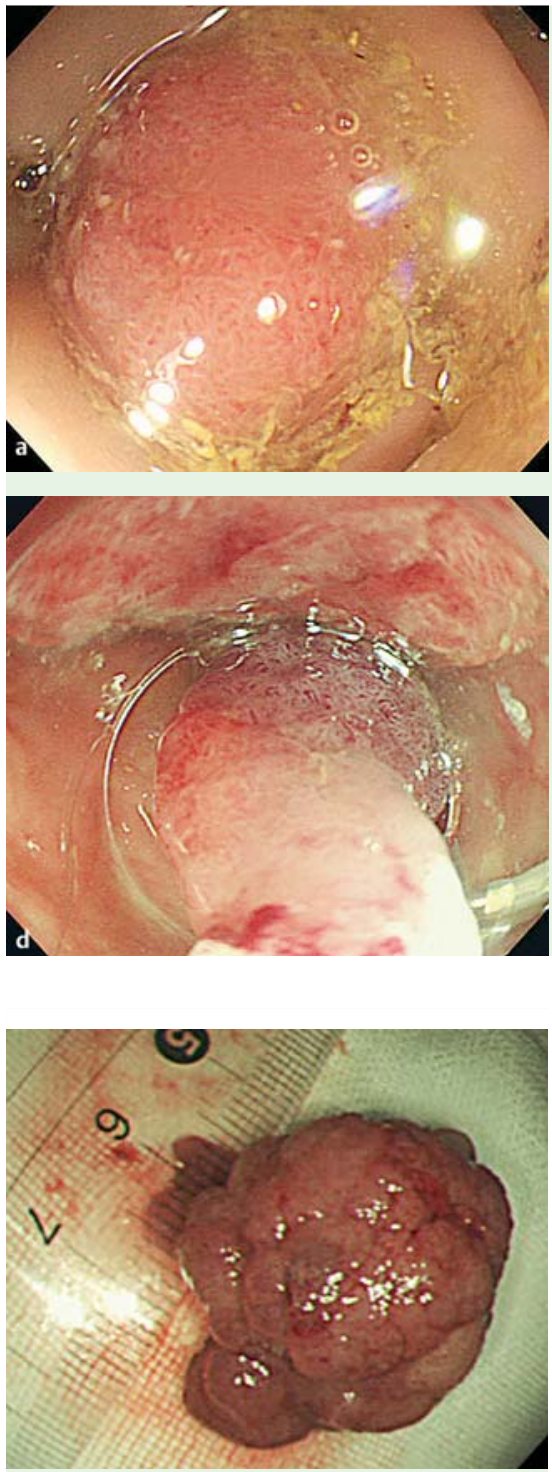

Fig. 2 The resected polyp was an intramucosal cancer of $30 \times 25 \times 25 \mathrm{~mm}$ in size.

An 83-year-old man presented with a feeling of abdominal fullness and underwent colonoscopy. Two pedunculated polyps were identified in the sigmoid colon: the one on the oral side was about $20 \mathrm{~mm}$, while that on the anal side was a giant lesion nearly as large as the diameter of the bowel lumen ( Fig. 1 a). It was judged to be difficult to perform polypectomy by snaring the latter polyp. Both polyps were therefore resected employing
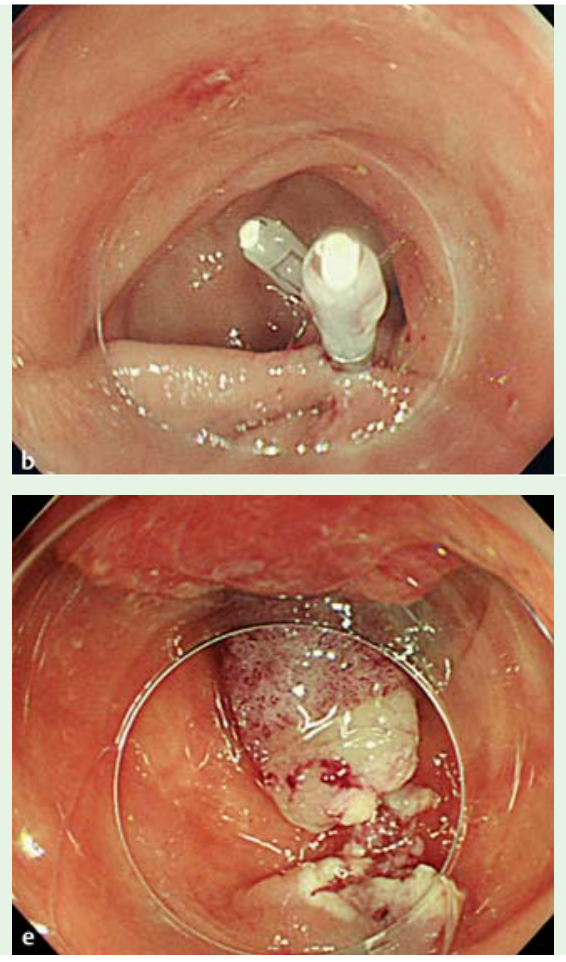

the following procedure. The end hood was placed on the scope, and multiple clips were placed around the base of the stalk to block blood flow ( Fig.1 b). Next, we pulled forward the stalk of the polyp by grasping the head of the polyp with the SB knife Jr (MD-47703; Sumitomo Bakelite, Akita, Japan) ( Fig.1c), pulling it into the end hood ( $\bullet$ Fig.1d), and performing electric incision until the polyp could be resected ( $\bullet$ Fig. 1 e). Stalk excision was performed with endocut mode $120 \mathrm{~W}$. Hemostatic treatment was performed with soft coagulation mode $80 \mathrm{~W}$.

Both polyps were found to be intramucosal cancers; their sizes were $20 \times 15 \times$ $10 \mathrm{~mm}$ and $30 \times 25 \times 25 \mathrm{~mm}$ ( Fig. 2). Both were judged to have been curatively resected.

While procedures using a two-channel scope or a needle knife are reported for the resection of giant pedunculated polyps for which snaring is impossible [1, 2], scissor-type forceps with a strong curve are useful in the sigmoid colon as they can be used without concern of per-

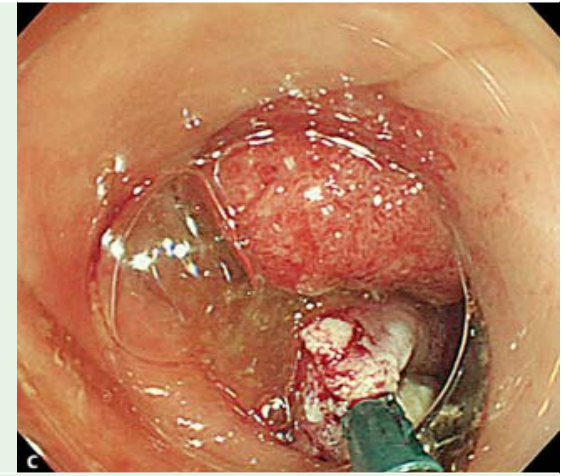

Fig. 1 Colonoscopy views showing: a a giant pedunculated polyp, nearly as large as the diameter of the bowel lumen, in the sigmoid colon; b multiple clips placed around base of the stalk; c the stalk area near the head of the polyp being grasped with a SB knife Jr; $\mathbf{d}$ the stalk being pulled into the end hood; $\mathbf{e}$ the base of the stalk after it had been separated by electric incision.

foration risk. The important points in this procedure are: (i) to obtain effective counter-traction by placing the end hood appropriately; (ii) to avoid misunderstanding the outflow of congested blood at the head of the polyp during incision as active hemorrhage; and (iii) after grasping with the scissor-type forceps, to pull the polyp forward and confirm that the normal large intestinal mucosa has not been grasped simultaneously and, finally, to perform the incision.

Endoscopy_UCTN_Code_TTT_1AQ_2AD

Competing interests: None

\section{Keiichiro Kume, Shintaro Takahashi, Keiichiro Kumamoto, Tatsuyuki Watanabe, Ichiro Yoshikawa, Masaru Harada}

Third Department of Internal Medicine, University of Occupational and Environmental Health, Japan, School of Medicine, Kitakyusyu, Japan 


\section{References}

1 Cipolletta L, Bianco MA, Rotondano G et al. Endoclip-assisted resection of large pedunculated colon polyps. Gastrointest Endosc 1999; 50: 405-406

2 Matsushita M, Takakuwa H, Matsubayashi Y et al. Handcrafted two-channel colonoscope for grasping-forceps-assisted resection of giant pedunculated polyps. Gastrointest Endosc 2005; 62: 132 - 136
Bibliography

Dol http://dx.doi.org/

10.1055/s-0034-1365381

Endoscopy 2014; 46: E290-E291

(c) Georg Thieme Verlag KG

Stuttgart · New York

ISSN 0013-726X

\section{Corresponding author}

\section{Keiichiro Kume, MD, PhD}

Third Department of Internal Medicine University of Occupational and Environmental Health, Japan

School of Medicine

1-1, Iseigaoka, Yahatanishi-ku

Kitakyusyu 807-8555

Japan

Fax: +81-93-6920107

k-kume@med.uoeh-u.ac.jp 